\title{
Weight and height growth velocities of Japanese boys and girls between age 7 and 14 years : a critical win- dow for early adolescent overweight risk
}

\author{
Takuro Nakano, Masako Sei, Ashraf A. Ewis, Hokuma Munakata, Chiemi Onishi, \\ and Yutaka Nakahori \\ Department of Human Genetics and Public Health, Institute of Health Biosciences, the University of \\ Tokushima Graduate School, Tokushima Japan.
}

\begin{abstract}
Childhood overweight is an important worldwide problem of public health concern, with metabolic, physical and psychosocial complications. More and more evidence is accumulating that children who gain weight rapidly earlier in life are at higher risk of becoming overweight later in adulthood life. Therefore, in a seven-year longitudinal study, we studied mid-childhood and early adolescence weight and height growth velocities among 5,024 Japanese $2^{\text {nd }}$ grade primary school boys and girls along with its effect on the likelihood of being overweight adolescents by the age of $14 \mathrm{y}$. Our findings showed that weight growth velocity of both sexes was associated with being overweight at the end of longitudinal study. Boys' risk of accelerated weight growth velocity and becoming overweight adolescents was almost doubled during ages $7 \sim 11 \mathrm{y}$ and become reduced afterward. Otherwise, odds ratios of girls' weight growth velocity peaks were found only at ages from 9 10 and 10 11 y. Thus, we suggest a critical window of mid-childhood period associated with adolescence risk of overweight, and we recommend that studying weight growth determinants during 7 11 y of boys and 9 11 y of girls may help in developing and applying proper programs for prevention and intervention of overweight problem. J. Med. Invest. 57 : 124-132, February, 2010
\end{abstract}

Keywords : growth velocity, overweight, Japanese, school children, longitudinal study

\section{INTRODUCTION}

Worldwide, the prevalence of overweight and obesity has become a problem of major public health concern. For instance, in developed countries and in Japan, overweight/obesity is gaining much attention for its increasingly reported associations with morbidity and mortality. More and more, evidence

Received for publication December 1, 2009 ; accepted January $12,2010$.

Address correspondence and reprint requests to Masako Sei, M.D., Ph.D., Department of Human Genetics and Public Health, Institute of Health Biosciences, the University of Tokushima Graduate School, Kuramoto-cho, Tokushima 770-8503, Japan and Fax : +81-88-633-7453. is accumulating that childhood overweight/obesity increases the risk of adulthood obesity which strongly correlated with cardiovascular diseases, metabolic syndrome, type 2 diabetes and other complications including cancers (1-16).

In children as well as adolescents, calculating the body mass index (BMI, $\mathrm{kg} / \mathrm{m}^{2}$ ) from body weight and height is a simple and acceptable screening method for detecting overweight and obesity. However, during childhood and early adolescence the BMI changes substantially with age, which makes setting BMI cut-off points for deciding overweight/ obesity a bit difficult. The pattern of weight and height growth during childhood period makes it 
difficult to have a definite prediction for the development of overweight/obesity later in life (17-21).

Assessment of weight and height growth in children may help to understand the potential periods of switching from being a normal weight and becoming an overweight/obese individual. Such understanding of the growth velocities is supposed to be helpful in developing preventive or therapeutic intervention programs.

In this research, we aimed at studying the weight and height growth velocities among Japanese school boys and girls. Therefore, we recruited a cohort of 5,024 school children from primary schools of Tokushima prefecture, Japan ; and followed up their weight and height growth velocities, annually, between the ages of 7 and 14 years.

For calculating overweight percentages among children of this study we used age and genderspecific BMI cut-off points starting from early childhood based on international data from different countries, which is linked to adults' cut-off points of BMI $>25$ for overweight and $>30$ for obese subjects (age adjusted BMI based on International Obesity Task Force (IOTF) standards) (22). Thus, in this study, children's weight, height and BMI were examined annually, and weight and height growth velocities were calculated during a 7-year longitudinal study and implications of these growth velocities to the subjects' current and future overweigh will be discussed.

\section{SUBJECTS AND METHODS}

\section{Subjects}

This study was designed to investigate the anthropometric growth velocities among school children at Tokushima prefecture. Further we aimed at comparing the anthropometric growth velocities of boys and girls as well as among normal, overweight and obese children to find out the age at which these Japanese children start to gain weight and develop overweight or obesity. For these purposes, we designed a longitudinal prospective cohort study that started on April, 2001 ; with a cohort of $2^{\text {nd }}$ grade primary school children i.e., 7 years old, who belonged to 232 primary schools in Tokushima prefecture, Shikoku Island, Japan.

Throughout the seven years cohort study, every year on the month of April, we assessed the anthropometric measurements (i.e., body weight and height) and calculated the BMI of every child in the study cohort. Then after the baseline study and from the consecutive annual anthropometric measurements weight and height growth velocities were calculated on 7 points of time throughout the longitudinal study (i.e., annual anthropometric weight and height growth velocities measurements).

Anthropometric measurements (weight and height) were conducted for the cohort school children by the school nurses. Children were allowed to wear only the underclothing during the measurements. Body weight was measured and recorded to the nearest $0.1 \mathrm{~kg}$, and height was measured and recorded to the nearest $0.1 \mathrm{~cm}$ using a manual height board. BMI was then computed for all the children using the formula; BMI equals weight (kg)/height $\left(\mathrm{m}^{2}\right)$.

The collected data were encoded according to the children's municipality, school, birth date and gender. The children identities were kept anonymous for ethical considerations ; therefore, we combined their anthropometric data during the seven years cohort study with their age, sex, birth date, municipality and school code.

Originally, this 7 years longitudinal study included a cohort of 7,506 children (3,855 boys and 3,651 girls), however, after omitting children with incomplete data and others from schools for children with special needs and those who remained unidentified after data combination trials, we could have full confirmed data of 5,024 children (2,601 boys and 2,423 girls). The omitted data have not biased the analyzed children data. Before starting this study we got the consent of Tokushima board of education as well as schools' administrations ; and the ethical committee of Tokushima University Hospital approved the study.

\section{Statistical methods}

Using BMI cut-off values according to the International Obesity Task Force by Cole et al. 2000, the children were classified as normal, overweight/ obese (22). At the baseline study and after the annual cross-sectional anthropometric measurements, the number of normal, overweight and obese children was calculated and prevalence of overweight/ obesity was determined. All analyses were done for the boys and girls, separately. Statistical analyses were performed using the software of statistical package for social sciences, SPSS ver11 (SPSS Inc.). Differences between boys and girls' measurements' means were analyzed by Student t-test. Weight and height growth velocities in four sub-groups at seven 
point of time were compared by Bonferroni's test if the one-way analysis of variance (ANOVA) test was significant. $P$ values less than 0.05 were considered significant.

Tracking of overweight or obesity was defined as being overweight from the baseline and throughout the longitudinal study till its final-year. In each age category the number of subjects who first met the criteria of overweight during the follow-up was analyzed. We also analyzed children weight and height at each year and subtracted it from the data of the previous year to calculate the growth velocity of weight and height of the Japanese school boys and girls.

For boys and girls, separately, and at different ages between 7 and $14 \mathrm{y}$, the children's weight and height growth velocities were investigated.

Then the likelihood of becoming overweight at the final year of the longitudinal study was investigated for the boys and girls who were initially non overweight. For this purpose we used a logistic regression model. The resulted odds ratios were used to draw a figure for boys and another figure for girls' odds ratios for becoming overweight at different ages between 7 and $14 \mathrm{y}$.

In all the statistical comparisons, p-values less than 0.05 were considered significant.

\section{RESULTS}

In this 7-year longitudinal study we started with a baseline study (on April, 2001) by measuring body weight, height and BMI for a cohort of school children whose ages were $7 \mathrm{y}$ old and belong to the $2^{\text {nd }}$ grade of primary schools at Tokushima prefecture, Japan. We followed up the 5,024 children $(2,601$ boys and 2,423 girls) whose data was full and confirmed. During the seven-year longitudinal study, we followed up body weight and height growth and monitored the growth velocity, separately for boys and girls.

Table 1 presents the means and standard deviations of the anthropometric measurements of the Japanese boys and girls including mainly body weight, height and BMI at every year starting from the baseline measurements on the year 2001 onwards for seven consecutive years i.e., from age 7 till the age of $14 \mathrm{y}$. Results indicate that at the age of 7 and $8 y$, boys have significantly higher body weight, height and BMI than girls. Then, at the age of $9 \mathrm{y}$ height and BMI of boys and girls become almost comparable. However, on the age of 10 and 11 y girls show accelerated height growth and become significantly taller but not heavier than boys, which makes the boys seem fatter having significantly higher BMI. This can be simply explained by the physiological trends for girls to start reaching maturity earlier than boys. This phenomenon was reversed completely by the age of $13 \sim 14 \mathrm{y}$ where boys weights and heights are significantly increased while their BMI was significantly reduced than girls.

Table 2 shows tracking status of overweight

Table 1 Mean BMI values of Japanese school boys and girls as measured in the baseline (2001) and the following annual crosssectional survey studies (2002-2008).

\begin{tabular}{|c|c|c|c|c|c|c|c|c|}
\hline \multicolumn{6}{|c|}{ Boys $(n=2,601)$} & \multicolumn{3}{|c|}{ Girls $(\mathrm{n}=2,423)$} \\
\hline Year & Grade & Age (y) & Height & Weight & BMI & Height & Weight & BMI \\
\hline 2001 & 2nd & 7 & $122.5 \pm 5.2^{* *}$ & $24.9 \pm 5.0$ ** & $16.5 \pm 2.4^{\text {** }}$ & $121.8 \pm 5.2$ & $24.2 \pm 4.5$ & $16.3 \pm 2.2$ \\
\hline 2002 & $3 r d$ & 8 & $128.1 \pm 5.4$ ** & $28.3 \pm 6.1$ ** & $17.1 \pm 2.8$ ** & $127.6 \pm 5.6$ & $27.5 \pm 5.6$ & $16.8 \pm 2.5$ \\
\hline 2003 & 4 th & 9 & $133.4 \pm 5.8$ & $31.8 \pm 7.3$ ** & $17.4 \pm 3.1$ & $133.7 \pm 6.3$ & $31.1 \pm 6.6$ & $17.3 \pm 2.7$ \\
\hline 2004 & 5 th & 10 & $139.0 \pm 6.2$ ** & $35.6 \pm 8.5$ & $18.3 \pm 3.3$ ** & $140.4 \pm 6.3$ & $35.8 \pm 7.5$ & $17.9 \pm 2.8$ \\
\hline 2005 & 6 th & 11 & $145.1 \pm 7.3^{* *}$ & $40.1 \pm 9.7$ & $18.9 \pm 3.4^{\text {** }}$ & $147.1 \pm 6.7$ & $40.5 \pm 8.7$ & $18.6 \pm 3.0$ \\
\hline 2006 & 7 th & 12 & $152.5 \pm 8.1$ * & $45.8 \pm 10.7$ * & $19.5 \pm 3.4$ & $152.0 \pm 6.0$ & $45.1 \pm 8.9$ & $19.5 \pm 3.2$ \\
\hline 2007 & 8th & 13 & $159.7 \pm 7.8^{* *}$ & $50.6 \pm 10.8^{* *}$ & $19.7 \pm 3.3$ ** & $154.9 \pm 5.5$ & $48.5 \pm 8.7$ & $20.2 \pm 3.2$ \\
\hline 2008 & 9 th & 14 & $165.1 \pm 6.7$ ** & $56.0 \pm 11.0$ ** & $20.4 \pm 3.4$ ** & $156.4 \pm 5.4$ & $51.4 \pm 8.6$ & $21.0 \pm 3.2$ \\
\hline
\end{tabular}

Data are expressed as the Mean \pm SD.

$P$ values were calculated by using Student's t-test.

* $\mathrm{p}<0.05$

** $\mathrm{p}<0.01$ 
Table 2 Tracking overweight status of Japanese school boys and girls from the baseline (2001) till the final year crosssectional cohort study (2008).

\begin{tabular}{ccc}
\hline Tracking status & Boys (n (\%)) & Girls (n (\%)) \\
\hline NOW-NOW & $1962(75.9)$ & $1885(77.8)$ \\
NOW-OW & $192(7.4)$ & $164(6.8)$ \\
OW-OW & $259(10.0)$ & $199(8.2)$ \\
OW-NOW & $188(7.2)$ & $175(7.2)$ \\
\hline Total & 2601 & 2423
\end{tabular}

among the children cohorts throughout the 7-years study. Tracking the BMI status of the children was performed by comparing their BMI at the baseline study with that of the final year measurements of the cohort study. Tracking BMI status resulted in having four sub-groups in each cohort of school boys and girls : children who were non-overweight at the baseline survey and were non-overweight at the end of the longitudinal study (NOW-NOW) ; children who were initially non-overweight but became overweight at the end of the study (NOWOW) ; children who were initially overweight and ended the study as overweight (OW-OW) ; and children who started as overweight at the baseline survey but ended up as non-overweight (OW-NOW) at the end of the 7-years longitudinal study i.e., at age of $14 \mathrm{y}$.

Among boys, 10.0\% were tracked as overweight (OW-OW) from the baseline survey till the final year, while for girls OW-OW group was $8.2 \%$.

There were $7.4 \%$ boys and $6.8 \%$ girls having normal weight at the baseline survey and have become overweight at the final year i.e., (NOW-OW).

A $7.2 \%$ of boys and a similar percent of girls who were initially overweight returned back to their normal BMI (OW-NOW) by the end of the longitudinal study. Deciding BMI tracking status was used in further studies on body weight and height growth velocities in normal (NOW-NOW) and overweight boys and girls, independently.

We compared height and weight growth velocities among the four sub-groups at seven point of time in each sex. By ANOVA test, significant differences were found in the height and weight growth velocities in almost all the checked time points for both sexes. In boys, we found that the height growth velocity of the four sub-groups started nearly the same at the baseline study. However, in the following years, all groups started to show their different peaks and patterns of height growth. At age of $12 \sim$ 13 y NOW-NOW boys showed their peak of height growth, which appeared a bit later than other subgroups and significantly higher than $\mathrm{OW}-\mathrm{OW}(\mathrm{p}<$ 0.01 ) and OW-NOW boys $(p<0.01)$ (Fig. 1A). Unlike height, boys' weight growth velocity of NOWNOW boys was significantly lower than other groups till the points of $10 \sim 11 \mathrm{y}$. The weight of the boys who started as normal and ended as overweight (NOW-OW) was rapidly growing after 11 12 y (Fig. 1B).

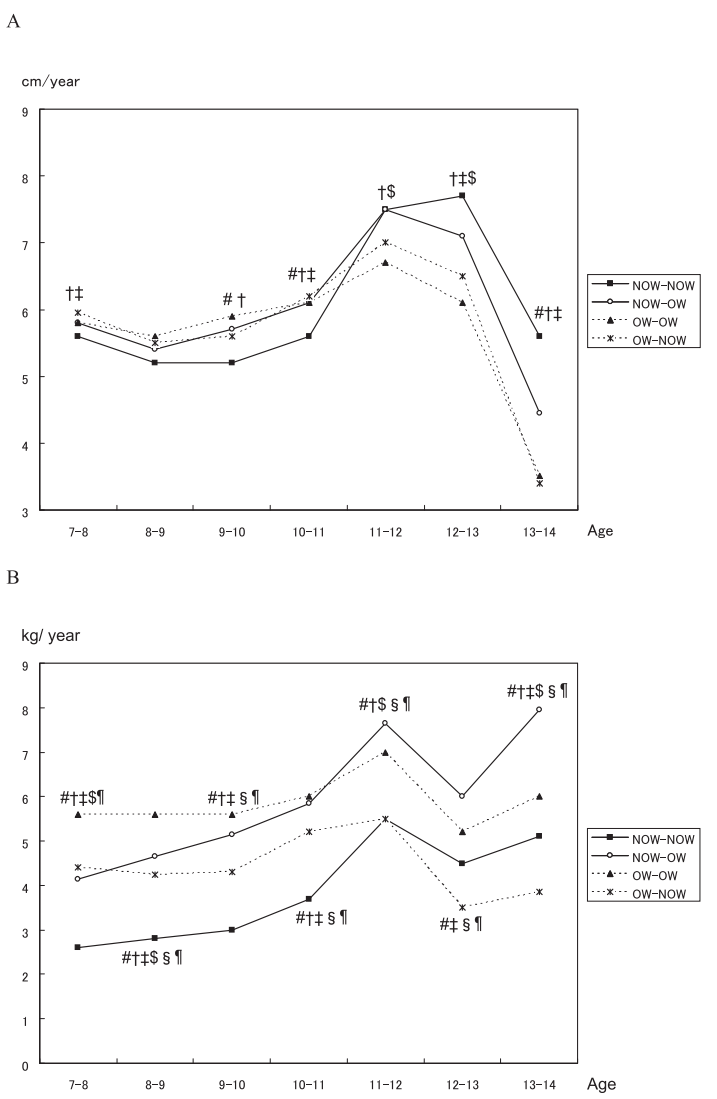

Fig. 1. A 7-years longitudinal follow up results of the studied Japanese boys' height (A) and weight (B) growth velocities among the four tracking sub-groups (2001 2008). \# $\mathrm{p}<0.05$, $\dagger \mathrm{p}<0.05, \ddagger \mathrm{p}<0.05, \$ \mathrm{p}<0.05, \S \mathrm{p}<0.05$, १ $\mathrm{p}<0.05$ for differences between NOW-NOW and NOW-OW, NOW-NOW and OW-OW, NOW-NOW and OW-NOW, NOW-OW and OW-OW, NOW-OW and OW-NOW, OW-OW and OW-NOW, respectively.

For girls, the height growth velocity of the four sub-groups was closely comparable throughout the study (Fig. 2A), but the weight growth velocity of OW-OW girls was significantly higher than other sub-groups at baseline and reached its peak at the age of $10 \sim 11 \mathrm{y}$. By the age of 9 10 y the NOWOW subgroups growth velocity significantly exceeded that of the OW-NOW and showed their peak at $10 \sim 11 \mathrm{y}$ and $11 \sim 12 \mathrm{y}$ while keeping significant increases than the other girls' sub-groups till the 
A
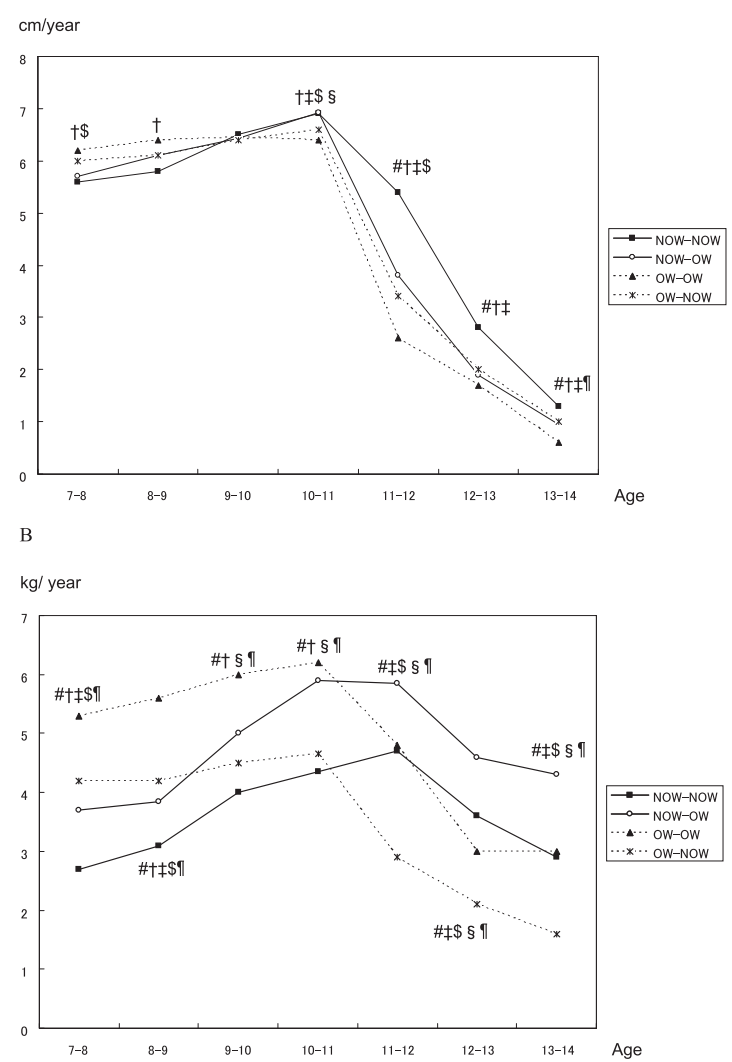

Fig. 2. A 7-years longitudinal follow up results of the studied Japanese girls' height (A) and weight (B) growth velocities among the four tracking sub-groups (2001 2008). \# $\mathrm{p}<0.05$, $\dagger \mathrm{p}<0.05, \ddagger \mathrm{p}<0.05, \$ \mathrm{p}<0.05, \S \mathrm{p}<0.05$, ๆ $\mathrm{p}<0.05$ for differences between NOW-NOW and NOW-OW, NOW-NOW and OW-OW, NOW-NOW and OW-NOW, NOW-OW and OW-OW, NOW-OW and OW-NOW, OW-OW and OW-NOW, respectively.

end of the longitudinal study (Fig. 2B).

Table 3 shows odds ratio/1-SD increase in weight growth velocity of the initially non overweight boys and girls (NOW-NOW and NOW-OW tracking subgroups), throughout the seven-year longitudinal study. It indicates the children's likelihood of becoming overweight at different points during their ages between 7 14 y. For boys, the "odds ratio" of gaining weight rapidly and becoming an overweight boy was almost doubled at each point throughout the period from ages $7 \sim 11 \mathrm{y}$, then the risk is relatively reduced through the early adolescence period. However, for girls, the pattern of weight growth velocity and the likelihood for being an overweight was different. The peak of the girls' likelihood of becoming overweight at the final year of the longitudinal study was found at ages from $9 \sim 10 \mathrm{y}$ and $10 \sim 11 \mathrm{y}$. Odds ratio distribution patterns per each year from the age of $7 \sim 14 \mathrm{y}$ for boys and girls are presented in figure $3 \mathrm{~A}$ and $3 \mathrm{~B}$, respectively.
Table 3 Seven-years risk of Japanese boys and girls for becoming overweight by the age of $14 \mathrm{y}$; odds ratios for 1 -SD increase in weight growth velocity and $95 \%$ CIs at different ages between 7 and $14 \mathrm{y}$.

\begin{tabular}{ccccc} 
Boys \\
\hline Age & Odds ratio & $95 \%$ CI & p value & 1-SD (kg/year) \\
\hline $7-8$ & 2.69 & $2.26-3.03$ & $>0.01$ & 1.72 \\
$8-9$ & 1.98 & $1.68-2.32$ & $>0.01$ & 2.28 \\
$9-10$ & 2.39 & $1.97-2.88$ & $>0.01$ & 2.61 \\
$10-11$ & 2.05 & $1.73-2.44$ & $>0.01$ & 3.05 \\
$11-12$ & 1.69 & $1.45-1.97$ & $>0.01$ & 4.40 \\
$12-13$ & 1.17 & $1.01-1.34$ & 0.04 & 4.05 \\
$13-14$ & 2.55 & $2.13-3.05$ & $>0.01$ & 5.30 \\
\hline
\end{tabular}

Girls

\begin{tabular}{ccccc}
\hline Age & Odds ratio & $95 \% \mathrm{CI}$ & $\mathrm{p}$ value & $1-\mathrm{SD}(\mathrm{kg} /$ year $)$ \\
\hline $7-8$ & 1.87 & $1.57-2.22$ & $>0.01$ & 1.74 \\
$8-9$ & 1.89 & $1.55-2.31$ & $>0.01$ & 1.87 \\
$9-10$ & 2.69 & $2.34-3.23$ & $>0.01$ & 2.70 \\
$10-11$ & 2.87 & $2.37-3.37$ & $>0.01$ & 3.56 \\
$11-12$ & 1.51 & $1.30-1.85$ & $>0.01$ & 3.79 \\
$12-13$ & 1.44 & $1.21-1.72$ & $>0.01$ & 3.10 \\
$13-14$ & 1.95 & $1.67-2.29$ & $>0.01$ & 2.07 \\
\hline
\end{tabular}

A
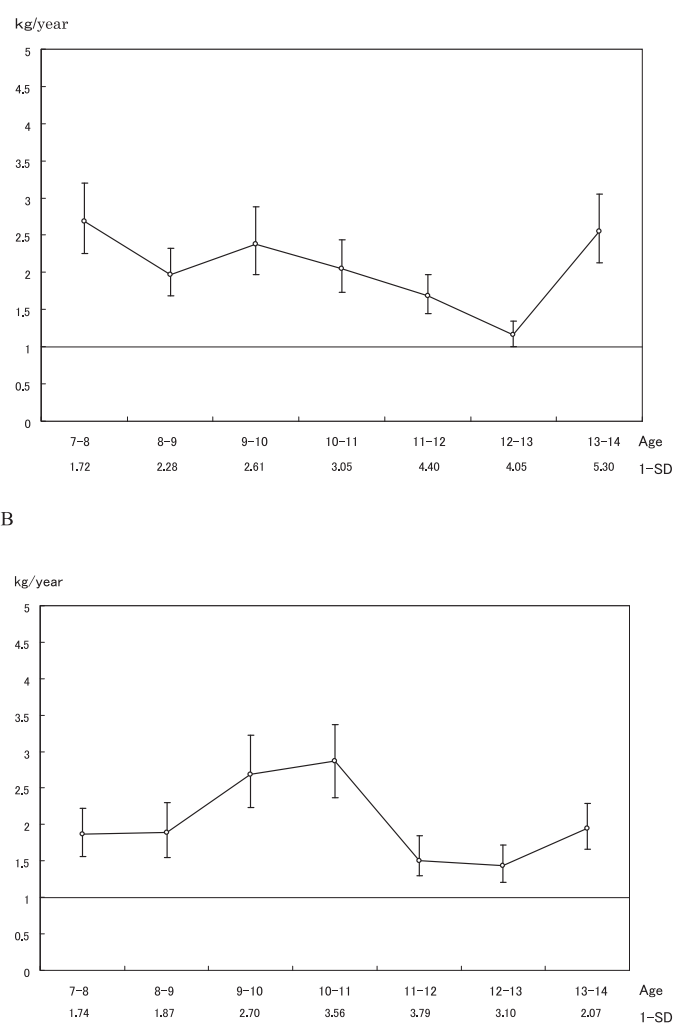

Fig. 3. Seven-years odds ratios for the initially non overweight boys (A) and girls (B) for becoming overweight by the end of the longitudinal study. Odds ratio/1-SD increase in weight growth velocity at any point of time between ages of 7 and $14 \mathrm{y}$ indicates the risk of being overweight at the end of the 7 -year longitudinal study. 


\section{DISCUSSION}

Childhood overweight is an important worldwide problem of public health concern, with metabolic, physical and psychosocial consequences (23-25). It has also, become manifested from the accumulating data that overweight children are significantly more likely to become overweight or obese adults (26-30). Moreover, several studies are accumulating more evidence indicating that children who gain weight rapidly earlier in life are at higher risk of becoming overweight or obese later in adulthood life (31-37). Therefore, studies that focus on growth velocities are thought to be helpful for overweight and obesity researchers to find out the proper periods for applying prevention and intervention programs to control overweight problem. Some researchers have already focused on the postnatal and early childhood weight and height growth velocities among children and studied its relationship with adolescent body fatness. They concluded that there are two main critical periods of early childhood associated with the later risk of obesity : up to 6 months after birth and from $2 \mathrm{y}$ onward till 5 years of age (38).

In our study, we aimed at studying mid-childhood and early adolescence weight and height growth velocities among Japanese school boys and girls along with its effect on the likelihood of being overweight adolescents.

Therefore, we studied body weight, height and BMI of 5,024 Japanese $2^{\text {nd }}$ grade primary school children (2,601 boys and 2,423 girls) from Tokushima prefecture in a baseline study, on April, 2001, and followed up their anthropometric measurements in a seven-year longitudinal study. The boys and girls weight and height growth velocities were calculated and comparisons were performed among four tracking subgroups decided by following up their initial BMI status at the baseline survey and at the end of the longitudinal study.

We found that at the ages of $7 \sim 8$ years boys had more overweight than girls, but on the age of 9 years the differences disappear since in this age it is physiologically known that girls start to grow faster before puberty. However, on the age of 10 11 girls' height but not weight growth becomes accelerated than boys; therefore the boys were fatter on this period. In the early adolescence period boys weight and height growth are significantly accelerated than girls. These periods of earlier girls puberty at the age of 9 and the boys pubertal age is a bit later than them is consistence with the known physiological trends (39-42).

Tracking the children's BMI status from the baseline to the end of the 7-year longitudinal study was performed by comparing their BMI at the baseline with that of the final year measurements. Tracking status investigation showed that $10 \%$ of $7 \mathrm{y}$ overweight Japanese primary school boys tracked into overweight $14 \mathrm{y}$ adolescents. This percentage was lower among girls, where, $8.2 \%$ of $7 \mathrm{y}$ overweight primary school girls tracked into overweight $14 \mathrm{y}$ adolescents. These results indicate that the prevalence of overweight is higher among Japanese boys, whose childhood overweight is more tracked to early adolescence than the Japanese girls of the same age (43).

The children tracking status resulted in having four sub-groups in each cohort of school boys and girls : NOW-NOW, NOW-OW, OW-OW and OWNOW.

Further, we investigated height and weight growth velocities among boys and girls and compared the height and weight growth velocities among the BMI tracking four sub-groups.

For boys, the height and weight growth velocities were significantly different among the four subgroups in almost points. It was obvious that the NOW-NOW boys had their height growth peak at $12 \sim 13 \mathrm{y}$ which was later than boys of the other 3 sub-groups (Fig. 1A). For their body weight, OWOW and OW-NOW groups showed parallel weight growth velocity, while from the initial measurements weight growth velocity of OW-OW was significantly higher than that of OW-NOW. A similar trend of weight growth velocity was observed for the two groups who were initially NOW. Thus, the curves of NOW-NOW and NOW-OW weight growth velocities were almost parallel in all the measurements points. The curve of NOW-OW weight growth velocity was differentially higher and the difference increases from the age of $11 \mathrm{y}$ onward (Fig. 1B).

These results seem to be supported by other research finding from Japan, which reported that childhood obesity was increasing in Japanese boys, especially those who aged $9 \sim 11 \mathrm{y}$; and those studies additionally, reported that approximately $32 \%$ of the obese boys and $41 \%$ of the obese girls grow into obese adults, and the degree of obesity is a predictive factor for adult obesity (44).

For girls' weight growth velocity, girls who were initially overweight (OW-OW and OW-NOW) had parallel weight growth velocities curves with their 
peaks at age $10 \sim 11 \mathrm{y}$, while those who were initially non-overweight (NOW-NOW and NOW-OW) had parallel curves but their weight growth velocity peaks appeared later on ages 11 12 y (Fig. 2B). The girls' height growth velocity curves were significantly different, however these curves did not show noticeable differences among the four subgroups (Fig. 2A).

For further understanding of the weight and height growth velocities and their effects on the likelihood of boys and girls overweight status at the end of the 7-year longitudinal study, we used a logistic regression model to calculate odds ratios in the NOW-NOW and NOW-OW sub-groups of boys and girls.

The logistic regression model showed that the boys' risk of gaining weight and becoming overweight adolescents was almost doubled at each point throughout the period from the age of 7 till $11 \mathrm{y}$, and then the risk is relatively reduced through the early adolescence period. However, for girls, the pattern of weight growth velocities and the likelihood for being overweight adolescents were different, whereas, their peaks of "odds ratio" of becoming overweight at the final year of the longitudinal study was found only at ages from $9 \sim 10 \mathrm{y}$ and $10 \sim$ $11 \mathrm{y}$.

It must be clearly indicated here, that our study has a limitation of investigating weight and height growth velocities from children data between the ages of 7 and 14 years, which can not help in predicting the overweight status of those children beyond this age limit. Further studies with extended age ranges will follow to study the associations between height and weight growth velocities and adult BMI.

We can conclude that during the boys' age of 7 to $11 \mathrm{y}$ and girls' age of 9 to $10 \mathrm{y}$ body weight growth velocities seem to be associated with early adolescence overweight at the age of $14 \mathrm{y}$.

These results can suggest another critical window of mid-childhood period to be added to the current hypothesis of Button et al (2008) who hypothesized having two critical windows of early childhood associated with the later risk of overweight/obesity (38). We concluded that researches on overweight and obesity problems must take into considerations the periods of critical weight growth velocities to apply the proper preventive programs and plan for intervention strategies. This will be very helpful to concentrate the efforts to the target critical time windows of overweight problem.

\section{REFERENCES}

1. Ebbeling CB, Pawlak DB, Ludwig DS : Childhood obesity : public-health crisis, common sense sure. Lancet 360 : 473-482, 2002

2. Wang Y, Lobstein T : Worldwide trends in childhood overweight and obesity. Int J Pediatr Obes $1: 11-25,2006$

3. Hill JO, Wyatt HR, Reed GW, Peter JC : Obesity and environment: where do we go from here? Science 299 : 853-855, 2003

4. Ogden CL, Flegal KM, Carroll MD, Johnson $\mathrm{CL}$ : Prevalence and trends in overweight among US children and adolescents, 1999-2000. JAMA 288 : 1728-1732, 2002

5. Csábi G, Török K, Jeges S, Molnár D : Presence of metabolic cardiovascular syndrome in obese children. Eur J Pedatr 159 : 91-94, 2000

6. Matsushita Y, Yoshiike N, Kaneda F, Yoshita $\mathrm{K}$, Takimoto $\mathrm{H}$ : Trends in childhood obesity in Japan the last 25 years from the National Nutrition Survey. Obes Res $12: 205-214,2004$

7. Yoshinaga M, Shimago A, Koriyama C, Nomura Y, Miyata K, Hashiguchi J, Arima K : Rapid increase in the prevalence of obesity in elementary school children. Int J Obes Relat Metab Disord 28 : 494-499, 2004

8. Sugimori H, Yoshida K, Miyakawa M, Izuno T, Takahashi E, Nanri S : Temporal course of the development of obesity in Japanese school children : A cohort study based on the Keio Study. J Pediatr 134 : 749-754, 1999

9. Inokuchi M, Hasegawa T, Anzo M, Matsuo N. Standardized centile curves of body mass index for Japanese children and adolescents based on the 1978-1981 national survey data. Ann Hum Biol 33 : 444-453, 2006

10. Funatogawa I, Funatogawa T, Yano E : Do overweight children necessarily make overweight adults? Repeated cross sectional annual nationwide survey of Japanese girls and women over nearly six decades. BMJ 337 : a802. doi : 10.1136/bmj.a802, 2008

11. Sei M, Nakatsu T, Yuasa $K$, Tanaka $H$, INDRIANI, Munakata H, Nakahori Y : Prevalence of metabolic complications in children with severe obesity. Pediatr Int $49: 545-552$, 2007

12. Frontini MG, Bao W, Elkasabany A, Srinivasan SR, Berenson G : Comparison of weight-forheight indices as a measure of adiposity and cardiovascular risk from childhood to young 
adulthood : the Bogalusa heart study. J Clin Epidemiol 54 : 817-822, 2001

13. Sorof JM, Turner J, Martin DS, Garcia K, Garami Z, Alexandrov AV, Wan F, Portman $\mathrm{RJ}$ : Cardiovascular risk factors and sequelae in hypertensive children identified by referral versus school-based screening. Hypertension $43: 214-218,2004$

14. Ministry of Health, Labour and Welfare of Japan. Daiichi Publishing Co, Tokyo. The National Health and Nutrition Survey in Japan, 2006

15. Division of Health Promotion, Tokushima Prefectural Office, The Prefectural Health and Nutrition Survey in Tokushima, 2003, 2004

16. Ministry of Education, Culture, Sports, Science and Technology, National Printing Bureau, Tokyo, Report on School Health Survey 2006, 2007

17. Laskarzewski P, Morrison JA, Mellies MJ, Kelly K, Gartside PS, Khoury P, Glueck CJ : Relationships of measurements of body mass to plasma lipoproteins in schoolchildren and adults. Am J Epidemiol 111 : 395-406, 1980

18. Rolland-Cachera MF, Sempé M, GuilloudBataille M, Patois E, Péquignot-Guggenbuhl F, Fautrad V. Adiposity indices in children. Am J Clin Nutr 36 : 178-184, 1982

19. Hauspie RC : Mathematical models for the study of individual growth patterns. Rev Epidemiol Sante Publique 37 : 461-476, 1989

20. van Dommelen P, van Buuren S, Zandwijken GR, Verkerk PH : Individual growth curve models for assessing evidence-based referral criteria in growth monitoring. Stat Med 24 : 36633674, 2005

21. Valdez R, Greenlund KJ, Wattigney WA, Bao W, Berenson GS : Use of weight-for-height indices in children to predict adult overweight : the Bogalusa Heart Study. Int J Obes Relat Metab Disord 20 : 715-721, 1996

22. Cole TJ, Bellizzi MC, Flegal KM, Dietz WH : Establishing a standard definition for child overweight and obesity worldwide : international survey. BMJ 320 : 1240-1243, 2000

23. Must A, Jacques PF, Dallal GE, Bajema CJ, Dietz WH : Long-term morbidity and mortality of overweight adolescents. A follow-up of the Harvard Growth Study of 1922 to 1935. N Engl J Med 327 : 1350-1355, 1992

24. Cook S, Weitzman M, Auinger P, Nquyen M, Dietz WH : Prevalence of a metabolic syndrome phenotype in adolescents : findings from the third National Health and Nutrition Examination Survey, 1988-1994. Arch Pediatr Adolesc Med $157:$ 821-827, 2003

25. Bacha F, Saad R, Gungor N, Janosky J, Arslanian SA: Obesity, regional fat distribution, and syndrome $\mathrm{X}$ in obese black versus white adolescents : race differential in diabetogenic and atherogenic risk factors. J Clin Endocrinol Metab 88 : 2534-2540, 2003

26. Rolland-Cachera MF, Castetbon K, Arnault N, Bellisle F, Romano MC, Lehingue Y, Frelut ML, Hercberg S : Body mass index in 7-9-y-old French children : frequency of obesity, overweight and thinness. Int J Obes Relat Metab Disord 26 : 1610-1616, 2002

27. Stettler N, Zemel BS, Kumanyika S, Stalling VA: Infant weight gain and childhood overweight status in a multicenter, cohort study. Pediatrics 109 : 194-199, 2002

28. Singh AS, Mulder C, Twisk JW, van Mechelen $\mathrm{W}$, Chinapaw MJ : Tracking of childhood overweight into adulthood: a systematic review of the literature. Obes Rev $9:$ 474-488, 2008

29. Johannsson E, Arngrimsson SA, Thorsdottir I, Sveinsson $\mathrm{T}$ : Tracking of overweight from early childhood to adolescence in cohorts born 1988 and 1994 : overweight in a high birth weight population. Int J Obes (Lond) $30: 1265-1271$, 2006

30. Ferraro KF, Thorpe RJ Jr, Wilkinson JA : The life course of severe obesity : does childhood overweight matter? J Gerontol B Psychol Sci Soc Sci 58 : S110-119, 2003

31. Li H, Stein AD, Barnhart HX, Ramakrishnan $\mathrm{U}$, Martorell R: Associations between prenatal and postnatal growth and adult body size and composition. Am J Clin Nutr 77 : 1498-1505, 2003

32. Monteiro PO, Victora CG : Rapid growth in infancy and childhood and obesity in later life-a systematic review. Obes Rev 6 : 143-154, 2005

33. Dennison BA, Edmunds LS, Stratton HH, Pruzek RM : Rapid infant weight gain predicts childhood overweight. Obesity (Silver Spring) $14:$ 491-499, 2006

34. Reilly JJ, Armstrong J, Dorosty AR, Emmett PM, Ness A, Rogers I, Steer C, Sherriff A: Early life risk factors for obesity in childhood : cohort study BMJ. 330 : 1357, 2005

35. Sachdev HS, Fall CHD, Osmond C, Lakshmy R, Dey Biswas SK, Leary SD, Reddy KS, 
Barker DJ, Bhargava SK : Anthropometric indicators of body composition in young adults : relation to size at birth and serial measurements of body mass index in childhood in the New Delhi birth cohort. Am J Clin Nutr 82 : 456-466, 2005

36. McCarthy A, Hughes R, Tilling K, Davies D, Smith GD, Ben-Shlomo Y : Birth weight ; postnatal, infant, and childhood growth ; and obesity in young adulthood: evidence from the Barry Caerphilly Growth Study. Am J Clin Nutr 86 : 907-913, 2007

37. Corvalán C, Gregory CO, Ramirez-Zea M, Martorell R, Stein $\mathrm{AD}$ : Size at birth, infant, early and later childhood growth and adult body composition : a prospective study in a stunted population. Int J Epidemiol 36 : 550-557, 2007

38. Botton J, Heude B, Maccario J, Ducimetière $\mathrm{P}$, Charles $\mathrm{M}$ and FLVS Study group : Postnatal weight and height growth velocities at different ages between birth and $5 \mathrm{y}$ and body composition in adolescent boys and girls. Am J Clin Nutr 87 (6) : 1760-1768, 2008

39. Veldhuis JD, Roemmich JN, Richmond EJ, Rogol AD, Lovejoy JC, Sheffield-Moore M,
Mauras N, Bowers CY : Endocrine control of body composition in infancy, childhood, and puberty. Endocr Rev 26 : 114-146, 2005

40. Dietz WH : Periods of risk in childhood for the development of adult obesity-what do we need to learn? J Nutr 127(suppl) : 1884S-1886S, 1997

41. Ellis KJ, Nicolson M : Leptin levels and body fatness in children : effects of gender, ethinicity and sexual development. Pediatr Res 42 : 48, 1997

42. Hassink SG, Sheslow DV, de Lancey E, Opentanova I, Considine RV, Caro JF : Serum leptin in children with obesity : relationship to gender and development. Pediatrics 98 : 201203, 1996

43. Nakano T, Sei M, Ewis AA, Munakata H, Onishi C, Nakahori Y : Tracking overweight and obesity in Japanese children ; a six years longitudinal study. JMI 2010, "In press"

44. Kotani K, Nishida M, Yamashita S, Funahashi T, Fujioka S, Tokunaga K, Ishikawa K, Tarui S, Matsuzawa Y : Two decades of annual medical examinations in Japanese obese children : do obese children grow into obese adults? Int J Obes Relat Metab Disord 21 : 912-921, 1997 